\title{
Current concept of oral health and its potential implications for policy and practice of dental health coverage and insurance: Post COVID-19 measurement
}

Muhd Firdaus Che Musa, Noorhazayti Ab. Halim*, Syarifah Haizan Sayed Kamar, Zurainie Abllah, Salwana Supaat, Mohamad Shafiq Mohd Ibrahim

Kulliyyah of Dentistry, International Islamic University Malaysia, Department of Paediatric Dentistry and Dental Public Health, Pahang, Malaysia

\begin{abstract}
This review paper aims to succinctly discuss the current concept and definition of general and oral-health and its potential implications on policy and practice in regards to the dental health coverage/insurance post COVID-19 pandemic. In general, dental policies and coverage are treatment-oriented, largely focus on curative procedures with some portion for preventive care despite most of dental diseases being largely preventable. There is however still no universal consensus definition of health, leading to mixed-feeling in setting-up priorities and direction for health policy. The FDI-World Dental Federation has then published a new definition of oral-health, highlighting the broader determinants of oral-health and envisioning a discussion on the implications of this definition and, in particular, how to transform the new oral health framework into a policy and practice agenda. In Malaysia, it is predicted there will be increasing demand for public dental coverage post COVID-19, however the government is yet to be ready in fulfilling those needs, leading to worsening oral-health inequalities. The lack of healthcare expenditure with no health social-insurance model reduces the affordability and accessibility of patients to private services. Moreover, such narrow definition of oral-health, as influenced by the previous policies led to a limited coverage for common dental diseases, including oral health-related deformities linked to oral cancer and injuries. These are the major challenges for Malaysia. The government should therefore working in partnership, start subsidising dental fees of private health insurance, focus and integrate disease prevention and health promotion in order to achieve WHO-goal of universal health coverage.
\end{abstract}

Keywords: definition, oral health, perception, dental coverage, COVID19, Malaysia
Received:

7 September 2020

Revised:

29 December 2020

Accepted:

14 January 2021

Published Online:

28 February 2021

How to cite this article:

Che Musa, M. F. ., Ab. Halim, N. ., Sayed Kamar, S. H., Abllah, Z., Supaat, S., \& Mohd Ibrahim, M. S. . Current concept of oral health and its potential implications for policy and practice of dental health coverage and insurance: Post COVID-19 measurement. IIUM Journal of Orofacial and Health Sciences, 2(1), 4-13. $\underline{\text { https://doi.org/10.31436/ijoh }}$ s.v2i1.22

\section{Article DOI:}

https://doi.org/10.31436/ijoh s.v2i1.22

\section{Corresponding author:}

Address:

Department of Paediatric Dentistry \& Dental Public Health,

Kuliyyah of Dentistry,

International Islamic University Malaysia,

25200 Kuantan,

Telephone: $+609-5705523$ or +6019-9150909

Fax: +609- 5705580

Email address:

zetty@iium.edu.my 


\section{Global concept and definition of health}

There are numerous definitions and conceptual models developed to provide a holistic description of health, including psycho-social, ecological and biomedical concepts (Huber et al., 2011). However, there is still no universally accepted definition of health (Huber et al., 2011; Saracci, 1997). Commonly, health professionals and researchers have largely focused on the treatment of diseases through the perspectives of the biomedical model (Glick et al., 2012). Such concern nevertheless has created a narrow focus on the management of health and diseases (Glick \& Meyer, 2014; Huber et al., 2011). Nonetheless, over the years, the concept of health, including oral health, has evolved from the body's capacity to function into the mental, social, spiritual, emotional, and societal distinctive of health (Glick \& Meyer, 2014; Huber et al., 2011; Saracci, 1997). Addressing determinant for health is pivotal to reduce health inequalities within and across the countries (Marmot et al., 2012; Marmot et al., 2013).

At present, the World Health Organisation (WHO) defines health as the extent of an individual's or group's capacity to realise the aspirations and satisfy one's needs as well as to cope with the ever-changing environment. Thus, health is considered as a life necessity, rather than a resource and the present concept of health emphasises the importance of social and individual resources, along with physical capacities (WHO, 1984).

The way health is defined and interpreted by the public could be said to determine the nature and types of health services they need from the health practitioners (Glick et al., 2016; Lee et al., 2017). Several studies have found that there is higher public interest towards health and the public has become more aware on their health and well-being (Che Musa et al., 2020; Gallagher \& Wilson, 2009), and as a result they would like to participate in decision making over the treatment options offered to them (Watt et al., 2013). Nevertheless, their perception and interpretation of health needs as a layperson may differ from the view of professional evaluation that necessitates careful interpretation (Sheiham \& Tsakos, 2007); especially when planning and determining types of care could be provided and focused under the health insurance schemes and plans to improve patients' accessibility and affordability in seeking healthcare. Moreover, there is also an increasing awareness over the importance of social, general and oral health in a broader term to perform their daily routine and social activities without restriction, lead to better quality of life (Marmot et al., 2012; Watt, 2012). All of these have significant impact on health policy, research and service provision (Gallagher \& Eaton, 2015; Lee et al., 2017). Those increasing demand for health mainly due to high public expectation towards dental care and trend of the ageing population that associated with complex and chronic diseases, as well as general and oral health problems (Marcenes et al., 2013), need to be well-encountered given they may have special and complicated dental procedures (Ghezzi et al., 2017). As such various methods to assess healthcare should not be limited to the capability and capacity of health care provided by government only, but also from other payment mechanism such as health coverage and insurance. Moreover, out of pocket payment for even simple health procedures can often be quite expensive and limit their accessibility to better and high quality of care (Garla et al., 2014).

It is also widely recognized that demand on health care systems will always be greater than the resources available to meet these needs (Daly et al., 2013). It can be seen there exists health inequalities across and within both developed and developing countries. Inequalities are more significant in countries with a lower probability of unmet needs due to the lower public coverage for care provided by the government (OECD, 2020). Accessing for quality of medical care have undeniably played a significant role in determining health status in both rich and poor countries (Chin \& Mohd Noor, 2014; WHO and Commission on Social 
Determinants of Health, 2008); regardless of their economic status (Marmot, 2005; Wilkinson \& Marmot, 2003).

Therefore, the availability, affordability, accessibility, acceptability and accommodation to healthcare are a crucial and important factor to address health inequalities (Daly et al., 2013; Marmot, 2005). Understanding social and economic conditions, and other new trends of health determinants, as well as how the health is defined and interpreted is crucial to inform policy and practice, which could lead to better population health.

\section{Oral health definition and understanding}

Similarly, there seems to be a contradictory interpretation and understanding the concept and definition of oral health; especially towards the prevention and promotion of oral health among and between dental professionals and the public, including among dental stakeholders (Glick et al., 2016; Lee et al., 2017). As oral health is also a fundamental human right and has been recognised as an essential element for well-being in this millennia (Glick \& Meyer, 2014; Petersen, 2008), a universally accepted definition of oral health should reflect what oral health encompasses and how such definition may implicate the policies, research, education and clinical practices; in a way to improve people's quality of life (Lee et al., 2017; Patrick, 2017). Consequently, researchers and policymakers have used, modified, and developed several definitions of oral health based on the underlying and current concepts of general health.

Sheiham and Spencer (1997) described that oral health does not only reflects one's physical ability to painlessly and comfortably chew, taste and eat different foods, speak clearly, and have a fresh breathe, it also encompasses having a socially acceptable smile and dento-facial profile. This interpretation highly stressed those importance of social and oral health (Watt, 2012). In recent years, a broader bio- psychosocial model of health has emerged that states that interactions between biological, psychological, and social factors in determining the cause, manifestation, and outcome of wellness and diseases, which also significantly influenced policy, clinical practice and research (Huber et al., 2011).

In 2016, the FDI World Dental Federation has recognised the limitation of the previous interpretations and proposed their definition for oral health (Glick et al., 2016). The narrow definition of health and oral care has led to limited coverage on service provision and dental insurance, which subsequently leads to accessibility issues among population with greatest needs, or presented with complex health problems, especially oral health-related deformities linked to oral cancer and injuries, which has significant effects on patients' quality of life.

Glick and his colleagues (2016) summarised that FDI defined oral health as " $a$ multifaceted concept comprising of one's ability to taste, smell, smile, speak, touch, swallow and chew as well as the ability to confidently and painlessly show different emotions through facial expressions without any discomfort and craniofacial deformity. Oral health is also an important aspect of physical and mental wellbeing influenced by individual and societal values and attitudes of individuals and communities; [it] reflects the physiologic, social, and psychological attributes that are essential to quality of life; [it] is influenced by the individual's changing experiences, perceptions, expectations and ability to adapt to circumstances." In this light, widespread discussions and research are necessary if those dental components are to be useful and translatable into practice and policy of dental health coverage/insurance in order to improve patients' accessibility, lead to better care management of patients with complex dental health care needs.

The proposed framework of the FDI definition is deemed as a more comprehensive framework and it should help to move oral health into the mainstream and strengthen the effectiveness of advocacy for better oral health and oral health equity. By recognising the importance of tackling 
social and economic condition; and shared common risk factors (Watt, 2012), as advocated by current concept and definition of health. It also places oral health at the centre of strategies to address the both the global burden of non-communicable and oral diseases (Glick et al., 2016). Such development has opened the opportunity to discuss the impact of such definitions to oral health and how to translate the new oral health framework into practice. In addressing health inequalities in dentistry, public and private sector need to work together in recognising those shared social determinants and common risk factors (Watt, 2012), to improve accessibility and affordability for dental care through the provision of an alternative payment system as part of the dental health coverage and insurance.

\section{COVID-19 and dental insurance}

With the COVID-19 pandemic, it had a strong influence on the utilization of dental services (Guo et al., 2020; Passarelli et al., 2020). As employees lose their jobs due to COVID-19, many is expected to lose their employersponsored dental insurance; thus, their access to dental care. It is more pronounced in states that have not expanded medical scheme insurance or do not even offer dental benefits for adults (Choi et al., 2021).

With these predictable changes in dental insurance coverage, there will be expected changes in types of dental procedures performed at dental practices following the COVID-19 pandemic (Choi et al., 2021); as it had a strong influence on the utilization especially for emergency dental services (Guo et al., 2020). In general, fewer patients visited the dental for both urgency and nonurgency cases at the beginning of the COVID19 pandemic than before (Ahmadi et al., 2020; Choi et al., 2021; Passarelli et al., 2020). Whereas, in the US, it was reported that the average dental practice would experience decreases in routine check-up visits but increases in tooth extraction, a procedure that is greatly used by uninsured patients or through publicly insured (Choi et al., 2021). This could be explained due to the evidence that the proportion of dental and oral infection were reported to raise from pre to during COVID-19 (Guo et al., 2020). As such, regularly refining the fundamental of dental health insurance policy is critically needed wider discussion among key policymakers to improve the affordability and accessibility of patients towards the dental care.

\section{Insurance principles and dental care}

Inherently, global oral health care is mostly provided by private dental practitioners and the treatment cost is high. A total increase in general health expenditure was reported across OECD countries, specifically for private health expenditure, (OECD, 2017, 2020). For dentistry, the use of dental care is low and it is relative to the existing need mainly because of the high cost of dental services (Bommireddy et al., 2014; Brennan et al., 2008). Hence, dental prepayment programmes or insurance schemes are considered an effective mechanism for extending dental services to more people (Garla et al., 2014; Gnanamanickam et al., 2018).

Insurance has grown in prominence and evolved over time from pay-for-service as the main method of payment to an alternative form of payment, which is private health insurance (Gnanamanickam et al., 2018). Private insurance transfers the cost risk to the insurer company through scheme applied and chosen by the patients. Thus, such third-party payment for dental services is made to the dentist by an agency, rather than directly by the patient. The third party could be referred to as a private carrier such as an insurance company, or also the government as part of the public financing of dental care (Garla et al., 2014). Insurance cover for dental services is typically provided under general treatment cover which can be purchased separately, or as part of a combined health policy with hospital cover Nevertheless, cash payment of service fees is still the dominant form of payment in many developing countries and it is preferred in many instances since the payment is made immediately (Garla et al., 2014). 
Private health insurance plays a key role in financing dental care in certain countries. Adult dental care in countries such as Australia, United States, Canada and New Zealand, are mainly based on private health insurance and not part of the basic package of public care insurance, although some care is provided for individuals with disabilities, low-income and underprivileged groups. Whereas, other countries such as the UK and Nordic countries provide public dental care particularly to children and underprivileged groups. Meanwhile, in other countries, prevention and treatment are covered under the private insurance and the cost is shared among the patients. As such, low-income groups without insured face difficulties in accessing dental care (OECD, 2011, 2015), and therefore require support from the government.

The provision of private dental insurance has been associated with higher levels of access to dental care, more frequent checkup visits and receiving a favourable quality of services (Garla et al., 2014). There is a positive association between dental insurance and frequent dental visits. Adults with dental insurance in Australia are likely to have more regular access to dental care and have a more favourable pattern of service uses than those uninsured (Gnanamanickam et al., 2018). Having dental coverage and insurance leads to more consistent dental care. As access to dental care is important to general health, the government could subsidise some of the payment for the private health insurance (Garla et al., 2014). In a nutshell, dental care insurance should focus on providing more access to essential preventive care, lowering costs for other procedures, and maintaining patients' overall wellbeing (Stancil et al., 2005); as well as ensuring universal health coverage (UHC) of its people. UHC does not mean free coverage for all possible health interventions, regardless of the cost, as there is no country can provide all services free of charge on a sustainable basis. UHC should encompasses all components of the health system such as service delivery systems, the health workforce, health facilities and communications networks, health technologies, information systems, quality assurance mechanisms, and governance and legislation (DGHS, 2017; WHO, 2015).

\section{Situation of Malaysia}

In general, Malaysia relatively has not practiced dental health insurance systems as overall (Che Musa et al., 2019). Adult and elderly groups who choose dental care in private practices need to pay using their own pocket-money. Out of pocket payment for even simple dental procedures can often be quite expensive and very few insurers will inevitably embrace dental coverage as part of the benefits in their plans. Furthermore, only a limited number of private organisations (employers) provide basic dental coverage that subsidise dental care as part of their employee benefit often for routine care such as annual tooth cleaning and fillings; whereas serious dental problems usually remain the responsibility of the individual to pay for (Che Musa et al., 2018; Ministry of Health Malaysia, 2013; Oral Health Division Malaysia, 2005).

They are few notable insurers for dental coverage in Malaysia provided by few companies such as by Allianz Care, TuneProtect in collaboration with Universal MediDent Sdn Bhd (UMDSB) and Malaysia Dental Health Insurance. Nevertheless, their existence is unknown locally and unattractive probably due to some of the schemes being offered are yet comprehensive enough to offer holistic dental benefits or dental protection in Malaysia. Hence, the prevention of dental diseases, such as common and complex dental diseases such as dental caries and periodontium diseases, and oral health related deformities linked to oral cancer and injuries are commonly missed from the health insurance coverage.

This is probably the available policies are restricted and determined and interpreted differently by non-health groups or general health professionals, instead of oral health experts. As a result, oral health is defined and translated into private health scheme in a very rigid way. Narrow interpretation of oral health description among oral health practitioners also could further restricting 
the dimensions of those private health insurance policy.

The oral healthcare system in Malaysia involves both public and private agencies and organisations (Oral Health Division Malaysia, 2006). The Oral Health Programme (OHP), under the Ministry of Health $(\mathrm{MOH})$ is the leading public agency responsible for providing health and oral care to the Malaysian population through its primary, specialist, and community oral healthcare programmes (Oral Health Division Malaysia, 2005, 2006). All Malaysians are eligible to receive publicly funded dental services, which provide highly subsidised basic dental treatments like fillings, extractions, low-cost dentures, and emergency care. The target groups for public dental services are toddlers, preschool children, primary and secondary school students, antenatal mothers, adults and elderly people, as well as special care groups who are mentally, physically or economically disadvantaged. All school children aged 18 years and below will receive dental treatment provided by dental therapists under the School Dental Programme, which offers free dental check-ups and treatment, with parental consent (Malaysian Dental Council, 2018; Oral Health Division Malaysia, 2005). Whilst the oral health planning is widely considered across targeted groups, nevertheless only $23.7 \%$ of the total Malaysian population utilised the dental service in 2019; majority of them visited public sector and $15.0 \%$ have never received dental care (Ministry of Health Malaysia, 2020); indicating poor accessibility of Malaysian population to dental care and services.

As a middle-income country with a growing and ageing population (Department of Statistics Malaysia, 2011), Malaysia has recorded significant levels of oral diseases such as dental caries and periodontal disease, even though there are indications that dental caries is declining in certain agegroups (Dental Service Division Malaysia, 1990; Oral Health Division Malaysia, 2004, 2013). With increasing need and demand for inexpensive, curative public funded dental care, there is evidence that the dental waiting list for subsidised dental care in Malaysia has increased over time (Malaysian Dental Council, 2014). The situation seemed to get worst during the COVID-19 pandemic as only non-generating aerosol dental procedure was allowed in adherence to medical/dental recommendations (Clarkson et al., 2020). Moreover, many patients only visit dental facilities on an emergency basis or when they experience pain due to cost issues (Locker, 1989; Watt, 2007, 2012). Adults and the elderly may choose private dental care need to pay using their own money as there is a long waitlist to access public dental care.

In addition, private health insurance providers should provide wider coverage for oral cancer and trauma cases. General cancer cases are on the rise and this is reflected in the higher number of insurance claims in the country (Abdul Karim, 2016). There is less or none evidence whether this claim including oral cancer cases. In Malaysia, malignant neoplasms account for $10.6 \%$ of deaths at government hospitals (Omar et al., 2006); and Indians ethnicity were reported to be at the highest risk of oral cancer, followed by the Indigenous people of East Malaysia (Zain et al., 1997). As mentioned, oral cancer can seriously affect the quality of life of its sufferers. Due to the important functional and social role of the oral cavity and its related structures, oral cancer can be even more debilitating than other forms of cancer (Johnson, 2001). In this regard, the most difficult challenge in managing oral cancer is creating the delicate balance between arresting disease progression and not compromising the patient's quality of life (Bjordal et al., 1994). Patients are often willing to accept a reduced lifespan, rather than compromise their quality of life drastically, as oral cancer will affect how they speak, eat, and swallow (Meek et al., 2000). This message is clear and could not be ignored by insurance policymakers. Therefore, understanding the functional, socio-psychological and physical effects of oral cancer through inputs from the medical and dental specialists would assist them in appreciating the value that sufferers attach to different aspects of their health-related quality of life. Subsequently, more insurance 
company should offer cancer protection plans that also account for oral cancer, or even evolving and broadening their coverage to more types and stages of cancer. It is also worth to know that Malaysians indeed are underinsured and inadequately protected which about only $22 \%$ have medical insurance and critical illness coverage (Abdul Karim, 2016).

Besides oral cancer, injuries like a missing front tooth might be considered lightly by the insurance company. Moreover, about $5.4 \%$ of 12-year-olds reported injuries to anterior teeth in 2007 (Oral Health Division Malaysia, 2010). In this sense, the front tooth perfects one's smile and presents the first impression of one's facial profile and his ability to speak properly. Therefore, a missing front tooth or a canine tooth as a result of an accident should be considered as an acquired facial deformity and should be covered by the insurance company as it actually affects one's quality of life. In this regard, oral health professional should move from previous non-dynamic oral health definition to accommodate current/contemporary issues on how oral health affects population's quality of life and moves beyond teeth-related definitions to a bigger, more practical and comprehensive definition by including oral health as a true subset of general health.

In the meantime, the lack of government spending on oral healthcare has created concerns over the government's ability to meet the increasing needs of the population. In this light, while the government has constantly called for increasing access to dental care, it has only provided a small allocation for dental health for over 40 years since 1970 (Oral Health Division Malaysia, 2005). The recent data in 2016 reported that only $9.44 \%$ of the total national budget has been allocated to the $\mathrm{MOH}$, while the expenditure for healthcare is equivalent to $4.55 \%$ of the gross domestic product (GDP) (Ministry of Health Malaysia, 2017). It is projected that such expenses will be incurred until 2030 and this encompasses $4.4 \%$ of the GDP (Ministry of Health Malaysia, 2013). While there is uncertainty following unstable political climate at present, it is hoped that the recent budget tabled and approved is hoped to contribute to positive changes in dental healthcare.

\section{Major challenges for Malaysia}

It is expected and predicted that more people will prefer to visit public sector during and post COVID -19 pandemic, however the government is yet to be ready in fulfilling those needs, leading to worsening of health outcome and inequalities in oral health. This is where the role of private is pivotal to support the public oral care in promoting oral health and wellbeing of the population. However, the lack of government spending on health and dental insurance in the country reduces the affordability and accessibility to private services (Institute for Public Health, 2012). There is some constraint with available options for dental payment mechanism in the country which may limit the opportunity to assess the dental care. As such, there is a slow movement of patients towards the private sector. The privatisation of the future health system is also at stake due to the conflicts between politicians, public, professional expectations and health policies. The proposed change from the subsidised model of healthcare to the health social insurance model may poorly steer the local dental market towards privatisation (Ministry of Health Malaysia, 2013); and it is remained undoubtedly till now. Moreover, such narrow definition of health and oral care, as influenced by the previous policy and politics, has led to a limited coverage on dental diseases, including oral health related deformities linked to oral cancer and injuries. These are the major challenges for Malaysia.

Considering the restrictions on health funding, dental facilities and payment mechanism; prevention of disease and health promotion is necessary. This indicates the needs for stakeholders and health providers to tackle this issue effectively and efficiently. The government should and work across sectors and organisations and start subsidising dental fees charged to private health insurance, including companies involved with the 
dental insurance. The focus should be on prevention of common oral diseases and promotion of health, including oral health related deformities linked to oral cancer and injuries in the private health scheme to ensure quality of care, thus achieving and universal health coverage of its people.

\section{Conclusion}

This paper illustrates the shift in concept and current understanding of general and oral health; and the implications it has on the policy and practice in regards to dental health insurance/coverage post COVID-19 pandemic. Based on the current understanding on the concept for oral health, it is crucial for key stakeholders working together in recognising the importance of tackling social and economic condition; and shared common risk factors as advocated by the current concept for health. The shift in focus provides an opportunity for oral health care to be placed at the centre of strategies to address not only the dental diseases, but also the global burden of non-communicable diseases in tackling oral health inequalities of its nation. The dental prepayment programmes or insurance schemes should be considered by many countries as an alternative and beneficial mechanism to reduce oral health inequalities and extending dental services to more people, including Malaysia with lower public dental coverage, increasing demands, limited dental facilities and escalating health expenditure. The Malaysian government should therefore consider the possibility of supporting private dental health insurance by allocating and subsidising payment incurred to needy insurers and focusing on prevention oriented-treatment of common dental diseases, as well as covering oral health related deformities linked to oral cancer and dental injuries to ensure and achieve WHO goal of universal health coverage for its nation.

\section{References}

Abdul Karim, N. A. (2016). Insurance: Cancer protection plans in Malaysia (Pt 1). The Edge Malaysia.
Ahmadi, H., Ebrahimi, A., Ghorbani, F. (2020). The impact of COVID-19 pandemic on dental practice in Iran: a questionnaire-based report. BMC Oral Health, 20(1), 354.

Bjordal, K., Kaasa, S., Mastekaasa, A. (1994). Quality of life in patients treated for head and neck cancer: a follow-up study 7 to 11 years after radiotherapy. International Journal of Radiation Oncology Biology Physics, 28(4), 847-856.

Bommireddy, V. S., Pachava, S., Ravoori, S., Sanikommu, S., Talluri, D., Vinnakota, N. R. (2014). Socioeconomic Status, Needs, and Utilization of Dental Services among Rural Adults in a Primary Health Center Area in Southern India. Journal of International Oral Health, 6(6), 56-60.

Brennan, D. S., Luzzi, L., Roberts-Thomson, K. F. (2008). Dental service patterns among private and public adult patients in Australia. BMC Health Services Research, 8, 1.

Che Musa, M. F., Bernabe, E., Gallagher, J. E. (2020). The dental workforce in Malaysia: drivers for change from the perspectives of key stakeholders. International Dental Journal, 70(5), 360-373.

Che Musa, M. F., Hassan, Y. F., Sayed Kamar, S. H., Abllah, Z., Supa'at, S., Rahman, F., et al. (2019). Situation, challenges and potential reforms for healthcare systems of Malaysia and Bangladesh: overview of dental counterpart. Journal of Biotechnology and Strategic Health Research, 3(3), 225-236.

Che Musa, M. F., Hassan, Y. R., Rahman, F., Jeenia, F. T. (2018). Provision of Health and Dental Care in Two Middle Income Asian Countries. Journal of Biotechnology and Strategic Health Research, 2(3), 182-188.

Chin, V. Y. W., Mohd Noor, N. A. (2014). Sociocultural determinants of health and illness: A theoretical inquiry. Malaysian Journal of Society and Space, 10(1), 49-59.

Choi, S. E., Simon, L., Riedy, C. A., Barrow, J. R. (2021). Modeling the Impact of COVID-19 on Dental Insurance Coverage and Utilization. Journal of Dental Research, 100(1), 50-57.

Clarkson, J., Ramsay, C., Richards, D., Robertson, C., Aceves-Martins, M. (2020). Aerosol Generating Procedures and their Mitigation in International Dental Guidance Documents - A Rapid Review. Cochrone Oral Health.

Daly, B., Watt, R., Batchelor, P., Treasure, E. T. (2013). Essential Dental Public Health. New York: Oxford University press.

Dental Service Division Malaysia. (1990). Dental Epidemiological Survey of Adults in Malaysia. Kuala Lumpur: Ministry of Health Malaysia

Department of Statistics Malaysia. (2011). Population Distribution and Basic Demographic Characteristics Report 2010. Retrieved 1 April 2013, from http://www.statistics.gov.my

DGHS. (2017). Universal health coverage (UHC); Bangladesh on path to UHC. In: Journey to SDGs 2030 for health. Dhaka, Bangladesh: Directorate General of Health Services. Retrieved from 21 July 2019, from 
http://www.dghs.gov.bd/images/docs/Publ icaations/JourneytoSDGs2030\%20forHealth _Fin_ed2.pdf

Gallagher, J. E., Eaton, K. A. (2015). Health workforce governance and oral health: Diversity and challenges in Europe. Health Policy, 119(12), 1565-1575.

Gallagher, J. E., Wilson, N. H. F. (2009). The future dental workforce? British Dental Journal, 206(4), 195-199.

Garla, B. K., Satish, G., Divya, K. T. (2014). Dental insurance: A systematic review. Journal of International Society of Preventive \& Community Dentistry, 4(Suppl 2), S73-77.

Ghezzi, E. M., Kobayashi, K., Park, D. Y., Srisilapanan, P. (2017). Oral healthcare systems for an ageing population: concepts and challenges. International Dental Journal, 67 Suppl 2, 2633.

Glick, M., Meyer, D. M. (2014). Defining oral health: a prerequisite for any health policy. The Journal of the American Dental Association, 145(6), 519-520.

Glick, M., Monteiro da Silva, O., Seeberger, G. K., Xu, T., Pucca, G., Williams, D. M., et al. (2012). FDI Vision 2020: Shaping the future of oral health. International Dental Journal, 62(6), 278-291.

Glick, M., Williams, D. M., Kleinman, D. V., Vujicic, M., Watt, R. G., Weyant, R. J. (2016). A new definition for oral health developed by the FDI World Dental Federation opens the door to a universal definition of oral health. International Dental Journal, 66(6), 322-324.

Gnanamanickam, E. S., Teusner, D. N., Arrow, P. G., Brennan, D. S. (2018). Dental insurance, service use and health outcomes in Australia: a systematic review. Australian Dental Journal, 63(1), 4-13.

Guo, H., Zhou, Y., Liu, X., Tan, J. (2020). The impact of the COVID-19 epidemic on the utilization of emergency dental services. Journal of Dental Sciences.

Huber, M., Knottnerus, J. A., Green, L., van der Horst, H., Jadad, A. R., Kromhout, D., et al. (2011). How should we define health? The British Medical Journal, 343, d4163.

Institute for Public Health. (2012). National Health and Morbidity Survey 2011. Retrieved 1 December 2014, from http://repository.um.edu.my/22698/1/NH MS2011 research\%20team.pdf

Johnson, N. W. (2001). Global epidemiology. In Oral Cancer (pp. 1-30). London: Blackwell Publishing.

Lee, J. Y., Watt, R. G., Williams, D. M., Giannobile, W. V. (2017). A New Definition for Oral Health: Implications for Clinical Practice, Policy, and Research. Journal of Dental Research, 96(2), 125-127.

Locker, D. (1989). An introduction to behavioural science in dentistry. London: Tavistock/Routledge.

Malaysian Dental Council. (2014). Malaysian Dental Council Bulletin. Retrieved from Putrajaya:
Malaysian Dental Council. (2018). Dental Act 2018: Laws of Malaysia. Putrajaya: MDC. Retrieved 1 October 2020, from http://www.federalgazette.agc.gov.my/outp utaktap/aktaBI_20180626_AktaPergigianBI. pdf

Marcenes, W., Kassebaum, N. J., Bernabe, E., Flaxman, A., Naghavi, M., Lopez, A., et al. (2013). Global burden of oral conditions in 1990-2010: A systematic analysis. Journal of Dental Research, 92(7), 592-597.

Marmot, M. (2005). Social determinants of health inequalities. Lancet, 365(9464), 1099-1104.

Marmot, M., Allen, J., Bell, R., Bloomer, E., Goldblatt, P. (2012). WHO European review of social determinants of health and the health divide. Lancet, 380(9846), 1011-1029.

Marmot, M., Bell, R., Goldblatt, P. (2013). Action on the social determinants of health. Rev Epidemiol Sante Publique, 61 Suppl 3, S127-132.

Meek, P. M., Nail, L. M., Barsevick, A., Schwartz, A. L., Stephen, S., Whitmer, K., et al. (2000). Psychometric testing of fatigue instruments for use with cancer patients. Nursing Research, 49(4), 181-190.

Ministry of Health Malaysia. (2013). Malaysia Health Care Demand Analysis: Inequalities in Healthcare Demand \& Simulation of Trends and Impact of Potential Changes in Healthcare Spending. Retrieved 1 November 2014, from http://www.ihp.lk/publications/publication html?id=933

Ministry of Health Malaysia. (2017). Health Facts 2016. Retrieved 4 November 2018, from http://www.moh.gov.my/images/gallery/p ublications/HEALTH\%20FACTS\%202017.p df

Ministry of Health Malaysia. (2020). National Health and Morbidity Survey 2019 (fact Sheet): Noncommunicable diseases, healthcare demand and health literacy. Retrieved 27 November 2020, from http://iku.moh.gov.my/images/IKU/Docum ent/REPORT/NHMS2019/Fact Sheet NHMS 2019-English.pdf

OECD. (2011). Health at a Glance 2011: OECD Indicators. In. Retrieved 3 May 2014, from http://www.oecd.org/els/healthsystems/49105858.pdf

OECD. (2015). Health at a Glance 2015: OECD Indicators. In. Retrieved 3 May 2016, from http://www.keepeek.com/Digital-AssetManagement/oecd/social-issues-migrationhealth/health-at-a-glance2015 health glance-2015-en\#page124

OECD. (2017). Health at a Glance 2016: OECD Indicators. Retrieved 29 December 2020, from https://www.oecd-ilibrary.org/socialissues-migration-health/health-at-a-glance2017_health_glance-2017-en

OECD. (2020). Health at a Glance 2019: OECD Indicators. Retrieved 26 December 2020, from https://www.oecdilibrary.org/docserver/4dd50c09en.pdf?expires $=1608973430 \& i d=i d \& a c c n a$ 
$\underline{m e}=$ guest $\&$ checksum $=58749 \mathrm{DC} 36 \mathrm{E} 59 \mathrm{ECD} 4$ 87512AD587A49A2E

Omar, Z. A., Ali, Z. M., Tamin, N. S. I. (2006). Malaysian Cancer Statistics- Data and Figure Peninsula Malaysia 2006. Putrajaya: Ministry of Health Malaysia

Oral Health Division Malaysia. (2004). National Oral Health Survey of Adults 2000 (NOHSA 2000). Oral health status, impacts and treatment needs of Malaysian adults. Putrajaya: Ministry of Health Malaysia

Oral Health Division Malaysia. (2005). Oral Health Care in Malaysia. Putrajaya: Ministry of Health Malaysia

Oral Health Division Malaysia. (2006). Malaysia's National Oral Health Plan 2010. A lifetime of Healthy Smiles. Putrajaya: Ministry of Health Malaysia

Oral Health Division Malaysia. (2010). National Oral Health Survey of School Children 2007 (NOHSS 2007): 12 year olds. Putrajaya: Ministry of Health Malaysia

Oral Health Division Malaysia. (2013). National Oral Health Survey of Adults 2010 (NOHSA 2010). Putrajaya: Ministry of Health Malaysia

Passarelli, P. C., Rella, E., Manicone, P. F., Garcia-Godoy, F., D'Addona, A. (2020). The impact of the COVID-19 infection in dentistry. Experimental Biology and Medicine (Maywood), 245(11), 940-944.

Patrick, H. (2017). The New Definition of Oral Health and Relationship between Oral Health and Quality of Life. Chinese Journal of Dental Research, 20(4), 189-192.

Petersen, P. E. (2008). World Health Organization global policy for improvement of oral health-World Health Assembly 2007. International Dental Journal, 58(3), 115-121.

Saracci, R. (1997). The World Health Organisation needs to reconsider its definition of health. British Medical Journal, 314(7091), 14091410.

Sheiham, A., Spencer, A. J. (1997). Health needs assessment. In C. Pine (Ed.), Community Oral Health. Edinburgh: Elsevier Science Limited.
Sheiham, A., Tsakos, G. (2007). Oral health needs assessment. In C. Pine \& R. Harris (Eds.), Community Oral Health. Germany: Quintessence Publishing.

Stancil, T. R., Li, C. H., Hyman, J. J., Reid, B. C., Reichman, M. E. (2005). Dental insurance and clinical dental outcomes in NHANES III. Journal of Public Health Dentistry, 65(4), 189-195.

Watt, R. G. (2007). From victim blaming to upstream action: tackling the social determinants of oral health inequalities. Community Dentistry and Oral Epidemiology, 35(1), 1-11.

Watt, R. G. (2012). Social determinants of oral health inequalities: implications for action. Community Dentistry and Oral Epidemiology, 40 Suppl 2, 44-48.

Watt, R. G., Steele, J. G., Treasure, E. T., White, D. A., Pitts, N. B., Murray, J. J. (2013). Adult Dental Health Survey 2009: Implications of findings for clinical practice and oral health policy. British Dental Journal, 214(2), 71-75.

WHO. (1984). Health promotion : a discussion document on the concept and principles : summary report of the Working Group on Concept and Principles of Health Promotion. Copenhagen

WHO. (2015). Universal health coverage (UHC)- fact sheets. Retrieved 1 June 2016, from http://www.who.int/mediacentre/factsheet s/fs395/en/

WHO and Commission on Social Determinants of Health. (2008). Closing the gap in a generation. Retrieved from Geneve, Switzerland:

Wilkinson, R., Marmot, M. (2003). Socials Determinants of health: The Solid Facts. Retrieved from Denmark:

Zain, R. B., Ikeda, N., Razak, I. A., Axell, T., Majid, Z. A., Gupta, P. C., et al. (1997). A national epidemiological survey of oral mucosal lesions in Malaysia. Community Dentistry and Oral Epidemiology, 25(5), 377-383. 